\title{
INDEXING - A BIRDS EYE VIEW
}

\author{
Subhashini R M \\ Research scholar, Christ (Deemed to be University), Bangalore, India
}

ABSTRACT - Indexing is a quality determining factor. The concept is almost similar to registering, recording, etc. Indexing in a general context is a process to create indexes for record collection, which allows the researchers to search for the records of specific individuals. The main purpose of indexing is discovering the truth by building on previous discoveries, which enables the growth of faster learning, acknowledgement, interconnections and reputations of people involved in this. This article tries to create an understanding about indexing, its history, the types of indexing, the parameters involved and also discusses about the peer review method.

Keywords: Citation, indexing agencies, indexing, indexing parameters, peer review

\section{INTRODUCTION}

The concept of indexing is very simple as it reflects the quality of the journal that has been indexed. It is in itself a hallmark for the journals. The reputation of the journal is dependent on the indexing service and has a greater impact on the journal. Indexing in a general context is a process to create indexes for record collection, which allows the researchers to search for the records of specific individuals. The value of this is determined by those who use it, measuring its impact on the community as a whole. The repute of any journals would ideally depend on the number of such abstracting and indexing services that would cover it. The indexing service is like a product that the publisher can sell or can make it available in the market, a service that provides us with the information. [1]

Most of the journals claim to be indexed, but the era of the internet is flooded with several predatory journals, which to increase their publications, invites researchers to publish their works in these respective journals [2] [3]. A journal is well thought-out to be indexed only if it has been documented globally or regionally in the database. A database is a collection of information of various journal articles, an assemblage of large volumes of literature, that can be easily accessed, managed and updated in a machinereadable form. The indexed journals are considered to be more of scientific value or quality than the non-indexed journals as indexing helps to reach a wider audience of researchers and is available to all.

The word index is derived from the Latin word 'indicare' which means 'to point'. Indexing is also known as Citation index which is a list of articles that have been cited in an ordered list. The researchers can have an easy access to the records if the journals are indexed. The contents of the journal can be searched using keywords, title, headings, abstract, name of the author, etc. available in the database. An abstract, on the other hand, is the extended idea of indexing, shortening and summarizing the information. [4]

\section{HISTORY OF INDEXING}

The Hebrew religious literature was the evidence for the first citation index in the $12^{\text {th }}$ century. In the $18^{\text {th }}$ century, legal citations were recorded and citators like Shepards's citation made it popular. [1] However, the history of indexing dates back to the preprinting era, where the literature was handwritten, circulated among the people, the manuscripts written were not similar to each other because of the difference between the copywriters. Modern printing started in the year 1440, book indexing was in progress in the year 1460 and the bible concordance in the year 1470 . Samuel Johnson published the very first dictionary of the English language, also the very first index to the English language in 1755. In 1848, an American bibliographer William Frederick Poole, the precursor of modern indexing published his very own 154-page index to periodical literature. The Index Society was formed in London in 1877. In 1878, Benjamin Wheatley wrote 'What is an indexer', the Wheatley medal is popularly known after him. Paul Otlet, a Belgian author developed the 'Universal bibliographic repertory' in the year 1895 .

In the 1950s the concept of citation was led by three major factors. During World war II, a high influx of money towards research and development led to the documentation of findings of the published scientific journal literature. This rapid increase in literature created a need for indexing and retrieval of the data. The second factor was the dissatisfaction of the method of indexing that could not meet the needs of the active researchers. Also, there were limitations of subject indexing in terms of the retrieval. The third factor was the development of citation indexing. Dr Eugene Garfield, the founder and now Chairman Emeritus of Institute for Scientific Information (ISI) now Clarivate Analytics was involved in research related to machinegenerated indexes in the 1950s. It introduced the first citation index for papers that were published in journals. His objectivity of citation index might not have perceived well at the first glance then, but today it is considered as 
one of the most trusted and reliable sources of scientific knowledge. [5] The society of indexers was formed eventually in 1957 in Britain. The other indexing societies were formed thereafter in the USA as the American Society of Indexers, 1968; Australian Society of Indexers, 1976; Association of South African Indexers and Bibliographers, 1994. [6]

\section{INDEXING AGENCIES}

The biggest question is who records all this in the database, the answer to which is the indexing agencies. Many indexing agencies provide this service. Each has its policies, procedures, rules and regulations for indexing a journal. Following are some of the well-known indexing agencies, the policies, procedures and rules and regulation listed below.

SCI and SCI expanded: Published by ISI, it is a part of Thomson Reuters. The electronic version of this is called as 'Web of Science'. It has more than 8073 journals with citation references. [1]

Scopus: Scopus (Elsevier) is the most important indexing agency that has the largest database of research literature. A bibliographic database containing abstracts and citations of academic journals. Available online, updated almost every day, provides a range of tools for users to find the results. Covers 21,000 titles from over 5000 publishers. Allows researchers to search based on the domain, subject, author.

Indian citation index (ICI): Online citation data, a platform to measure the performance of Indian research periodically. Database launched in 2009, covers more than 800 journals.

Google scholar: A simple search tool for scholarly literature. Includes peer-reviewed journals, papers, thesis, books, reports, etc. A single platform through which one can search for the literature across various disciplines and sources. Helps to find the most relevant source covering the work done by researchers across the world. The level of search can be weighed down based on the full-text article, author, the date of publishing, how often it has been cited in other literature.

Crossref: An official agency that registers the DOI (Digital object identifier) for scholarly articles/publications. It covers millions of articles and other contents from several publications. It was launched in early 2000.

CABS (Current Awareness in Biological Science): It is a bibliographic database for biological research. Covers more than 1,700 journals and adds about 15,000 entries every month. [7]

Index Medicus/ Medline: It is published by the United States National Library of Medicine. It indexes medical scientific journals since 1879. [7]
OCLC (Online Computer Library Centre): It is a nonprofit computer library and research organization open for the public to access the information.

Pubmed: It is a free service from the US National Library of Medicine, includes citations from Medline and life science journals. It abstracts the reference from life science, biomedical topics. The indexer is the NCBI, contains more than 17 million titles. [7]

Ulrich's periodicals directory: It is a comprehensive serials directory and source of bibliographic and publisher information. It has 30,000 periodicals, including all types of journal articles (scholarly and academic articles), peerreviewed titles, open access publications, popular magazines, newspapers, newsletters. The database is updated weekly.

BIOSIS: BIOSIS, a bibliographic database defines life science or biology, covers journals across the broad subject area that includes zoology, botany, microbiology, agriculture, biochemistry, medicine, pharmacy to name a few. [8] [9]

DOAJ: Directory of open access journal, is an open directory that provides access and information to highquality peer-reviewed journals.

Some of the common features of the indexing agencies are:

1. Journals must have and e-ISSN (International Standard Serial Number) or P-ISSN

2. Journals should have a DOI (Digital object identifiers)

3. A copyright policy

4. An established publishing schedules

5. Academic contribution to the field

6. Clarity of the abstracts

7. Readability of the articles

8. Most of the indexing agencies choose English as the preferred language

9. Journal quality checks are at most mandatory

10. Quality of the journals to be of at most standards

11. The journal should stand right to its proposed aims and scope of the journal

12. Consideration for re-evaluation

\section{FUNCTION AND THE NEED OF INDEXING}

The primary function of indexing is to keep researchers, scholars and the students well informed about the latest and current information about literature regarding their subject. It is used as a retrospective search tool extensively by the scholars to locate information in the area of interest. The secondary functions are to help the users to identify the bibliographic details, to explore ideas and to obtain information from the database. It fulfils the need of scholars who require information about the subject from the earliest 
data available in resolving the research question and the problem undertaken for the research. The need of indexing also arises when the literature is available from a totally alien source, which the scholars cannot be self-satisfied with, at this time the indexing can save the time and effort of the scholars in locating the information.

\section{TYPES OF INDEXING}

There are different types of indexing, some of them are listed below.

1. Database or Bibliographic indexing: It is a platform that provides the indexers to record the journal articles. Has access to online literature. Helps to identify the information regarding the subject area through the details available, provides citation details of the article.

2. Geographical indexing: As the name suggests, it generates indexes for maps, atlases and cartographic material, that includes name of the place, historical details, topics, scale and coordinates.

3. Genealogical indexing: It helps to find out the original records, a user can locate the record using peoples name, location and dates. One can look up for family and personal relationship.

4. Legal indexing: Involves indexing legal subjects and materials. The indexers need to be familiar with the legal concepts.

5. Book indexing: A book index is a road map for a book. Indexing is done for the non-fictional books, textbooks, reports, multi-volume books, online books. The indexer needs to think logically and arranges the names, places and things in an alphabetical order, providing access to the detailed information of the contents of a book.

6. Subject gateways: It is an online academic directory that consist of the collection of websites for a specific subject. Unlike a normal search engine where both poor and good quality resources can be accessed, here the indexer creates subject gateways for specific subject area of interest.

7. Pictorial indexing: Indexes the images

8. Periodical and Newspaper indexing: An index that contains citations for the articles written in magazines, newspapers, journals and provides access to periodical articles by author or subject. [10]

\section{INDEXING PARAMETERS}

The quality and the authenticity of the journal can be understood by the indexing parameters. Helps the journals increase their visibility to a greater audience.

\section{Journal metric/Author metric}

The journal metric or the author metric can be classified into open ranking measures and closed ranking measures.

1. Open ranking measures

a. Impact factor: The impact factor is the measure of the frequency with which the average articles in a journal have been cited in a year. The journal impact factor cannot be calculated for a new journal, and is calculated only when the journal completes a minimum of 3 years of publication. It is not applicable to individual articles, rather only to the journals.

Impact factor $=$ The number of citations

Number of articles

b. Cite score: It was launched in 2016 and is based on the Scopus data. It is a simple way of measuring the citation impact on the serial titles. It is a measure that reflects the yearly average number of citations to recent articles published in that journal. It is based on the average citations received in a year

Cite score $\mathrm{Y}=$ Citations of the year $\mathrm{Y}$

Number of documents

published in 3 years

c. h-index: The h-index is also known as Hirsch index, measures the quality of the author and of the journal. It is simply the measure of the $\mathrm{N}$ publications that have the same number of citations. For example, an author's h-index is 5, which means that the author has published at least 5 articles that have been each cited 5 times at least.

d. $g$ index: The g index was developed by Leo Egghe, it is an improvisation of $\mathrm{h}$ index. It is calculated based on the distribution of the citation received by the authors publication, given that the articles are ranked in decreasing order of the number of citations that they received. It gives more weight to highly cited articles.

e. $m$ index: It is a variant of $\mathrm{h}$ index, that displays $\mathrm{h}$ index per year since the first publication.

f. h5 index: It is the maximum $\mathrm{h}$ such that $\mathrm{h}$ articles published in the last 5 complete years are cited at least $\mathrm{h}$ times each.

g. h5 median: h5 median for a publication is the median number of citations for the articles that make up its h5 index.

2. Closed ranking measures

a. SJR (SCImago Journal Rank): It is a portal that includes the journal and country specific indicators developed from the information contained

b. Eigen factor: It was developed by Jevin West and Carl Bergstrom. The Eigen factor is an overall rating of the importance of the scientific journals where all articles published in a journal are taken into consideration when calculating.

c. Article influence score: It measures the average influence, per article of the papers in the journal. It can be calculated by dividing the Eigen factor score by the number of articles published.

d. SNIP (Source normalized impact per paper): This indicator was created by Henk Moed. The SNIP measures the journal's contextual citation impact, which takes into account the characteristics of subject field, the rapidity of maturing of citation 
impact and also the extend to which the database used for the assessment covers the field literature.

\section{REVIEW METHODS}

The peer review method is also known as expert review, auditing or scientific review. The reviewers play a crucial role in administrating and validating the scholarly work. This method is used by the officials, journal editors to make a decision, evaluate and to improve the quality of the research. Despite a lot of criticism, it is the only method that is widely accepted.

\section{The peer review process}

The first step is, the author submits the paper to the journal, the journal checks if the paper meets the requirements of the journal. If the article does not meet the standards of the journal, then it will be rejected and is informed to the author. If yes, then the editor sends the paper to the reviewer. The reviewer's scans and evaluates the paper and will send the report to the editor, the editor then takes the further steps, to either accept, reject or send the article to the author for revision. The author makes revision and resubmits the paper, the editor or the reviewers re-evaluate the paper and send the recommendation to the editor to either reject or accept it. If rejected, the author is informed, if accepted, the paper is published and informed to the author. [11] [12]

The peer review can be distinguished into two major types;

1. Closed review: It is further classified into three types

a. Single blind review: It is the most common and traditional method of reviewing, where the author does not know who the reviewers are. It is kept hidden from the authors. This is done to ensure impartial decision. However, there are limitations where the author may feel the anonymity can lead to the reviewer publishing the work first.

b. Double blind review: In this case, both the reviewer and the author's identity are kept anonymous. This method reduces the bias, where the author's gender, country of origin is not revealed. A limitation with this is, the reviewer can identify a renowned author by his/her writing style.

c. Triple blind review: The reviewers are anonymous, also the author' identity is unknown to both the reviewer and the editor. Involves a lot of complexity in anonymizing the author or the article.

2. Open review: This model aims in transparency during the process of peer review. Both the author and the reviewer are known to each other. Most of them believe this to be the best way of reviewing as it provides a platform for open discussion.

\section{CONCLUSION}

The journals quality is determined by indexing, it surely has made the life of researchers easy and convenient. This article has given a brief idea about indexing, its history, concept, types, indexing agencies involved, indexing parameters and also on peer review process. Through indexing the researchers have access to millions of articles published in journal which makes the study possible. In the future, this article will guide researchers to understand the various concepts of indexing.

\section{REFERENCES}

[1] I. K. D. a. R. U. Haq, "What is indexing," Indian journal of orthopaedics, vol. 50, no. 2, pp. 115-116, March 2016.

[2] J. Beall, "BEALL'S LIST OF PREDATORY JOURNALS AND PUBLISHERS," [Online]. Available: OF PREDATORY JOURNALS AND PUBLISHERS.

[3] J. Beall, "Criteria for Determining Predatory Open-Access Publishers," 2015.

[4] N. Adetoro, Indexing and Abstracting, Open University, August 2014.

[5] E. GARFIELD, Concept of Citation Indexing: A Unique and Innovative Tool for Navigating the Research Literature, The Scientist, September 4, 1997.

[6] J. Simkin, "A brief history of indexing," ANZI, [Online]. Available: https://www.anzsi.org/about-indexing/a-briefhistory-of-indexing/. [Accessed 15 may 2020].

[7] "About indexing/abstracting," natureresearch. [Online]. [Accessed 15 may 2020].

[8] "BIOSIS Citation Index," Web of Science Group, [Online]. Available:

https://clarivate.com/webofsciencegroup/solutions/webodscie nce-biosis-citation-index/. [Accessed 15 May 2020].

[9] Freedman, "Growth and Change in the World's Biological Literature as Reflected in BIOSIS Publications".

[10 "Types of indexing," ANZSI, [Online]. Available:

] https://www.anzsi.org/about-indexing/types-indexing/. [Accessed 15 May 2020].

[11 "What is peer review?," Elsevier, [Online]. Available:

] https://www.elsevier.com/reviewers/what-is-peer-review. [Accessed 15 May 2020].

[12 R. Chenail, "Peer Review," in The SAGE Encyclopedia of

] Qualitative Research Methods, L. M. Given, Ed., Thousand Oaks, SAGE Publications, Inc. , 2012 , pp. 605-606. 